\title{
The performance of local contractors on high-value construction projects in Zambia: The case of selected infrastructure projects
}

\author{
Janis Kabwe, Professor Biemba Maliti, Engineer Dr Kasongo Mwale Richard* \\ a jkabwe2011@gmail.com, Lusaka 10101, Zambia
}

The Copperbelt University, Jambo Drive Campus, Kitwe, 10101, Zambia

University of Lusaka, Alick Nkhata Road, 10101, Lusaka, Zambia

\begin{abstract}
The study aimed to establish local contractors' performance on high-value construction projects. Therefore, a wide-range review of the extant literature was employed to obtain secondary data and understand the formulated problem. Further, the study was underpinned by the Pragmatism philosophy hence adopted a mixed-methods approach. This study had a population size of 383 , including clients, consultants, and contractors who are the major players in the construction industry. The Taro Yamane method for sample size calculation helped obtain a sample size of 196, and the questionnaire survey was adopted to acquire the primary data, with a response rate of $63 \%$ (123 respondents). The collected data were analysed using descriptive and inferential statistics, computed using IBM Statistical Package for the Social Sciences (SPSS). To analyse qualitative data, thematic analysis was adopted. Thus, the study concluded that organisational culture is a significant catalyst in the construction industry, and it influences the performance of contractors on high-value construction projects. The study further established that some of the significant challenges local contractors encounter in the construction industry included corruption, lack of technical expertise, lack of access to finance, poor organisational culture and low competitiveness. Furthermore, the study made an extensive contribution to the body of knowledge of the factors that influence the performance of contractors on high-value construction projects through some derived recommendations. Among the recommendations were the need to enhance the capacity building of local contractors through training and workshops, and the need for contractors to balance their organisational culture and their work culture and adopt a culture that allows them to be more reactive to their environment, especially to unexpected changes, to improve their performance.
\end{abstract}

Keywords: High-Value Construction Projects; Local Contractors; Performance; Organisational Culture; Challenges, Infrastructure

This article is an extract of the thesis submitted by Janis Kabwe to the School of Postgraduate Studies of the University of Lusaka in fulfillment of the requirement of the award of the Doctor of Philosophy Degree in Project Management. The research was supervised by the co-authors; Professor Maliti Biemba and Engineer Dr Kasongo Mwale Richard. 


\subsection{INTRODUCTION}

Organisations are increasingly considering new methods to expand products and processes to improve customer satisfaction and competitive performance in the existing scenario (Patyal and Koilakuntla, 2018). In the meantime, the construction industry provides a platform for competition for contractors (Edum-Fotwe et al., 2001). In respect of the preceding, there have been efforts by the Zambian government to ensure an enabling environment for local contractors in the construction industry. Policies such as The Citizens Economic Empowerment (preferential procurement) Regulations, National Council for Construction (NCC), Zambia Public Procurement Authority to ensure transparency, accountability, integrity, fairness, and public confidence in the procurement process have been set up by the Zambian government, (Report of the committee on communications, transport, works and supply, 2014). The most recent policy was the $20 \%$ subcontracting policy through a ministerial statement issued on 25 ${ }^{\text {th }}$ July 2012 to Road Development Agency (RDA) - allowing local contractors to participate in High-value construction projects of K30Million (RDA, 2015). Such policies' general goal is to contribute to sustainable economic development by building capacity in Zambian-owned companies. However, despite the introduction of initiatives outlined above, there has been little change recorded in the plight of the local contractors as they continue to face challenges in accessing plant and equipment, access to lines of credit, skilled personnel and construction management and organisation skills.

More so, some local contractors have failed to live up to their clientele' expectations to deliver fit for purpose construction projects despite these progressive efforts. After receiving high-value contracts, some local contractors betrayed their clientele' trust by abandoning the construction site (NCC, 2017). Consequently, much to the displeasure of clients/end-users, contractors and consultants, many projects experience extensive delays and exceed the initial time, cost and quality expectations. Local contractors experience the challenge of balancing time, coat, and quality, as evidenced by their continued abandonment projects upon receipt of the advance payment (ibid). The NCC contractor register indicates more local contractors than foreign contractors; however, the number of contracts awarded to them is negligible and requires immediate redress to facilitate the sustainable Zambian construction industry's development.

Further, there is a need to remove doubt among construction stakeholders who may view local contractor failure due to lousy work culture and a poor mindset. It appears that the inability of local contractors to execute projects efficiently or effectively has proved to be advantageous to the foreign contractors as they are thriving and getting all the contracts. To facilitate the government's intentions to re-scope existing projects, seek alternative financing to debt contraction, and increase local contractors' use to implement projects (KPMG, 2020), Zambian contractors have a considerable task ensuring that they remain competitive in 
today's construction industry. Therefore, there is a need to institute cultural studies in the construction industry. In the past, this awareness was heightened as the impact of other cultural processes became apparent, take the case of Cameron and Elington (1989) and Maloney and Federle (1993). While the primary focus is on management, it was expected in this study to establish the influence of culture on the performance of local contractors concerning delivering projects. However, studies into the influence of the culture of local contractors' performance at an industry level are limited, with a consequent little appreciation of the potentially powerful relationship of an industry's culture on the behaviour of individuals and organisations who consider themselves as part of the industry.

Simply put, the influence of culture and a need for mindset change amongst the contractors have received little or no attention. Hence, there is a need for the construction industry to adopt culture-oriented studies to understand why some of the contractors have continued to deliver projects that do not meet the contractual agreement and expectation. Additionally, the area-specific study of culture and its effects on contractor performance have not received adequate and comprehensive inspection concerning high-value construction projects in Zambia. Thus, it is imperative to focus on behaviours and actions that can be measured with ease to change the attitudes of local contractors towards projects.

\subsection{RESEARCH OBJECTIVES}

(i) Analyse the influence of culture on the performance of contractors on high-value construction projects; and

(ii) Analyse the significant challenges which local contractors encounter on high-value construction projects.

\subsection{RESEARCH QUESTIONS}

(i) What factors influence the performance of local contractors on construction projects?

(ii) How does culture influence the performance of contractors on high-value construction projects?

(iii) What challenges do local contractors encounter on high-value construction projects?

\subsection{LITERATURE REVIEW}

Execution of construction projects aims to accomplish set goals. Most projects involve the development of new infrastructure or the extension, refurbishment of existing structures. However, all projects have several objectives which are time-bound. For example, a project's objectives would include completion on time, within cost, and the delivery of acceptable quality to the client. The objectives are usually set at the project initiation stage and are the yardsticks for the success of the projects. Hence at the completion stage, an evaluation of the project objectives is instituted to ensure that the project met the set objectives. However, the 
literature suggests that not all projects satisfy the client as they may not be happy with the outcome. Some factors intervene to affect the attainment of objectives (Alqahtani et al., 2015); these intervening factors are the subject of this section of the study. From the customer's perspective, numerous essential behaviours define outstanding contractor performance. Many of the performance facets are input or "lead" factors or attitudes and behaviour rather than untainted construction competence. These include, but not limited to, delighting the customer's stakeholders, keeping business promises, aligning with the customer's culture, knowledge transfer to the group, and proving a keen understanding of the customer's business. This behavioural understanding has led to a change in the way customers interact with their first-tier contractors. By managing at this level, customers can vary and influence how their contractors develop as businesses (Butcher et al., 2010). King Matthew Eja and Manu Ramegowda (2019) highlighted that project failure occurs due to different reasons: inadequate project time, several scope changes, inadequate control, poor communication, sketchy stakeholder communication, Socio-Cultural and Political Interferences, and lack of top management support. These reasons relate to an organisational system, specifically organisational culture, project management culture, and the project manager's competencies. Furthermore, the project manager's performance is affected by the organisational culture and the project management culture. Thus, changes in these mentioned may affect the outcomes of the projects as well (Alqahtani Opt. Cit).

Furthermore, organisations' central resource is to conserve their competitive advantage (Sinclair and Sinclair, 2009, Barney, 1991). Thus, the prevailing literature point toward the notion that a relationship between organisational culture and organisational performance exists (Kemp and Dwyer, 2001). Since organisational culture has a significant role in work performance and effectiveness, the construction industry's low effectiveness may be related to the contractors' organisation culture; the culture-effectiveness (C-E) relationship has received increased attention in organisational research. Over the years of empirical research, scholars have established profuse relations between organisational culture and organisational performance. While previous businesses were either oblivious of culture's importance or believed it too difficult to manage, they currently distinguish that it can be useful for competitive advantage. Some organisations have understood this concept. By leveraging their culture of modernisation in the direction of the product and internal processes, they have survived despite the farfetched competition. They have been able to attempt new and profitable markets. However, to use culture strategically, a company first needs to understand its culture, and there lies the rub (Tharp, 2009). Organisational culture serves the leader by nurturing the value system created by him to both serving and incoming members. The critical view of culture at an organisational level is that it is influenced by those responsible for making procedures, standards and norms. Tharp (Opt. Cit) emphasises that using culture to improve performance lies in matching culture or attributes to organisational goals. 
Culture consists of two components: values and performance; the relationship between the two is that, while values are believed to be less tangible, there is a massive amount of evidence that higher performance results would be obtained through good values. Thus, in many organisations, culture regulates how the firm relates with its internal and external environment to pursue solutions to the organisation's concerns such as performance and survival (Joseph and Kibera, 2019). Fellows and Liu (2013) argue that culture conditions behaviour, and then behaviour adjusts culture. The consequence of this is the promotion of the enlightenment of the organisation's members. Hence, the generation of new answers to the questions related to performanceoriented in the firm. An organisation's culture is represented by the prevailing leadership styles, communication, organisational processes, structures, systems, and the specific definition of success in the views of particular organisations. Values and beliefs decide structures and systems created in an organisation, and the behaviour of the people behave concerning one another. On the contrary, structures and systems affect the attitude of organisational members (ibid). Furthermore, studies have shown that cultural elements differentiate between the best corporations and those just average. The average return for corporations with high culture and engagement is $50 \%$ higher profitability than those that do not have. The goal is not performance but an organisation that connects its people to the customers who express appreciation for that connection to purchase its products or services. Thus, values come first, and then performance in the form of financial measures, such as higher profitability, comes about due to aligned and delivered values that connect with the customer (McLoughlin and Miura, 2018). Besides, various researchers have investigated the impact of organisational culture on performance. Most of the literature concerning organisational culture hails from the last three decades of the 20th century. The notable papers include those from scholars such as the following: Hofstede (2007), Sułkowski (2012), Sikorski (2012), Cameron and Quinn (2003), Black (2003), and Boddy (2011). Consequently, many scholars emphasise that organisational culture is one of the indicators of the success of an organisation. The organisation's activity, efficiency and effectiveness in achieving its goals depend on the relationship between a few essential elements: employees and their qualifications, organisational structure, and culture. People shape the former two factors, and the organisational structure can be treated as permanent and unchangeable. In contrast, organisational culture is shaped by the daily conduct of the members of the organisation (Burkiewicz and Knap-Stefaniuk, 2020). Besides, although management theories have availed different kinds of organisational cultures, there are no ready-made programs of organisational culture that can be adapted to the particular needs of an institution. Every business develops its own specific organisational culture. Particular institutions may be part of a specific typology of culture, but the final shape depends only on themselves, and the decisive factor is a human being. Though mixed findings have been reported in the literature, Joseph and Kibera (2019) advance the argument that organisational 
culture supports the execution of strategy and acts as a shield against competitive imitation, thereby paving the way for superior performance outcome. Researchers of theories of organisational culture have developed various models and typologies that consider different characteristics of organisational culture, highlighted by grouping and logical organising. The most popular concepts and models are those proposed by Schein et al., (ibid). The Cameron/Quinn model of competing values is also a popular one (Cameron, Quinn, 2011).

Nevertheless, project management concerns managing a project, and a project is a unique endeavour to produce particular end products or deliverables within a specified time, cost and quality constraints (PMBOK, 2017). Based on this definition, a project's key distinguishing features include 'unique as they do not involve repetitive processes. Thus, every project is different from the last. Furthermore, each has a defined timescale, a specified start and end date within which the deliverables need to be produced to meet a specified customer requirement (ibid). In this author's opinion, it may be considered general knowledge that projects always have an approved budget to meet a specified customer requirement. Suffice to say, and projects have limited resources; hence they deal with uncertainty and therefore carry business risk. Furthermore, projects seek to achieve beneficial change, and this is because the purpose of a project is to improve an organisation or country through the implementation of business change.

Meanwhile, the significant interest of the general public when it comes to construction projects is time, cost, and quality. Their focus would be to see the project completed within cost, on time and of good quality. However, contractors have encountered several challenges in managing these parameters. Therefore, there is a need for construction industry professionals to ensure that they deliver quality works. For instance, the Republican President of Zambia officiated the new office building in Lusaka, ZED-Pre-Head Office, and expressed concern at the poor buildings by local Engineers and contractors. Despite the erected structures looking appealing, most of them were of the poor standard and exhibited shoddy craftsmanship. The president implored all those involved in the construction sector to uphold their professional ethics when discharging their duties (The Globe, 2019).

Moreover, managing projects comprises many activities that must be performed; (Pinto, 2007). Distinct project life cycle phases are Conceptualisation, Planning, Execution, and Termination, Monitoring and Controlling (which interfaces between execution and termination) (Project Management Institute, (PMI), 2014, PMBOK, 2017). Adding on to this, Irefin (2013) pointed out that project management integrates through these phases with the sole aim of making stakeholders and customer satisfaction. Indeed, effective project management is not a "one size fits all" approach; because it is a "common-sense approach," it must acclimatise to the changing project conditions; the rules of engagement for effectively managing projects are learned. Thus, there are many challenges in managing projects. According to Edgar (2021), a challenge is a 
problem; a challenge is the perceived gap between the current state and the sought-after state, or a deviation from a norm, standard, or status quo.

Consequently, the challenges of managing construction projects include the balancing of the complex elements of time, money, scope and people; which is one of the many jobs of the project manager, and other factors include client satisfaction, client changes, and health and safety (Cheung et al., 2004). More so, according to a universal study by Flyvbjerg et al., (2003) on construction project performance, identified as a significant problem was cost overrun where 9 of 10 projects were confronted with overrun ranges of 50 to $100 \%$. Additionally, problems such as shortage of human resources skills, inadequate supervision and site management, unsuitable leadership, and equipment failure have contributed to construction delays in many countries. The United Arab Emirates is reported to be one of the world's areas where such factors have been recorded (Faridi and El Sayegh, 2006). A study conducted in Palestine (UNRWA, 2006) established that local construction projects suffered from poor contractor performance for many reasons, such as the unavailability of materials, excessive amendments to plans and drawings, poor coordination amongst respondents, ineffective monitoring and feedback, and lack of leadership skills. The same is the case in the South African construction industry, as revealed by Hanson et al., (2003), who found that South Africa's building industry's clients were affected mainly by poor quality and contractor incompetence. Thus, customer satisfaction was negatively affected, and eventually, contractor performance and reputation were affected (Gharakhani et al., 2013). According to (Sichombo et al., 2009, Zambia Construction Analysis Report, 2014, and Construction Review online, 2021), the construction industry suffers from an inadequate supply of professionals, fewer skill levels of fresh graduates and a skilled labour force. High demand for professionals in many countries and low level of salary schemes in the local industry may reduce the number of professionals retained in the local construction industry. According to PricewaterhouseCoopers - (PWC) (2014), bribery and corruption are also deterrents to infrastructure investment in Africa. The PwC's 17th Annual Global CEO Survey discovered that Chief Executive Officers (CEOs) in Africa and Latin America and the Middle East are more apprehensive about bribery and corruption than those in the rest of the world. Despite the development of new policies and regulations in many jurisdictions, corruption and security concerns continue to be significant challenges in some countries.

Additionally, the Zambia Development Agency (ZDA) report of 2014 indicated that Zambia was facing challenges in implementing projects. The report categorically stated that often, construction projects managed by the government ran well over budget, behind schedule and changes to the project cost were often at the government's expense. For example, the RDA report (2016) highlighted that some projects experienced slow progress due to constrained cash flow. 


\subsection{CONCEPTUAL FRAMEWORK}

This study was tailored to the conceptualisation that High-Value Construction Projects (HVCPs) is the independent variable; thus, Local contractors have the task to manage the triple constraints of Time, Cost, and Quality encountered numerous challenges to do so. The framework also highlights culture, mindset and project management processes as the intervening variables. The background to this is that through literature review, recognised that construction project organisation is functioned by various individuals with a variety of backgrounds, triggering diverse human manners and different expectations for a project. Hence, individuals who come with complicated behaviours and attitudes significantly influence the success of the project.

Furthermore, literature resolved that cultural differences could produce clashes relating to individual communication, which reduces construction organisations' capacity to realise project objectives. In the same vein, literature identified that organisational culture plays an essential role in shaping the contractors and project teams. This study, therefore, argued that culture plays a vital role in the success or failure of project management. Thus, in the practice of project management, culture ought to be treated as a significant aspect at the controlling stage of the project, hence the requirement of mindset changes among local contractors if performance is to improve. In continuation, the dependent variable was local contractors' performance on HVCPs and measured in terms of project being on time, within cost, and meeting quality specifications. The following is the conceptual framework for this study: 


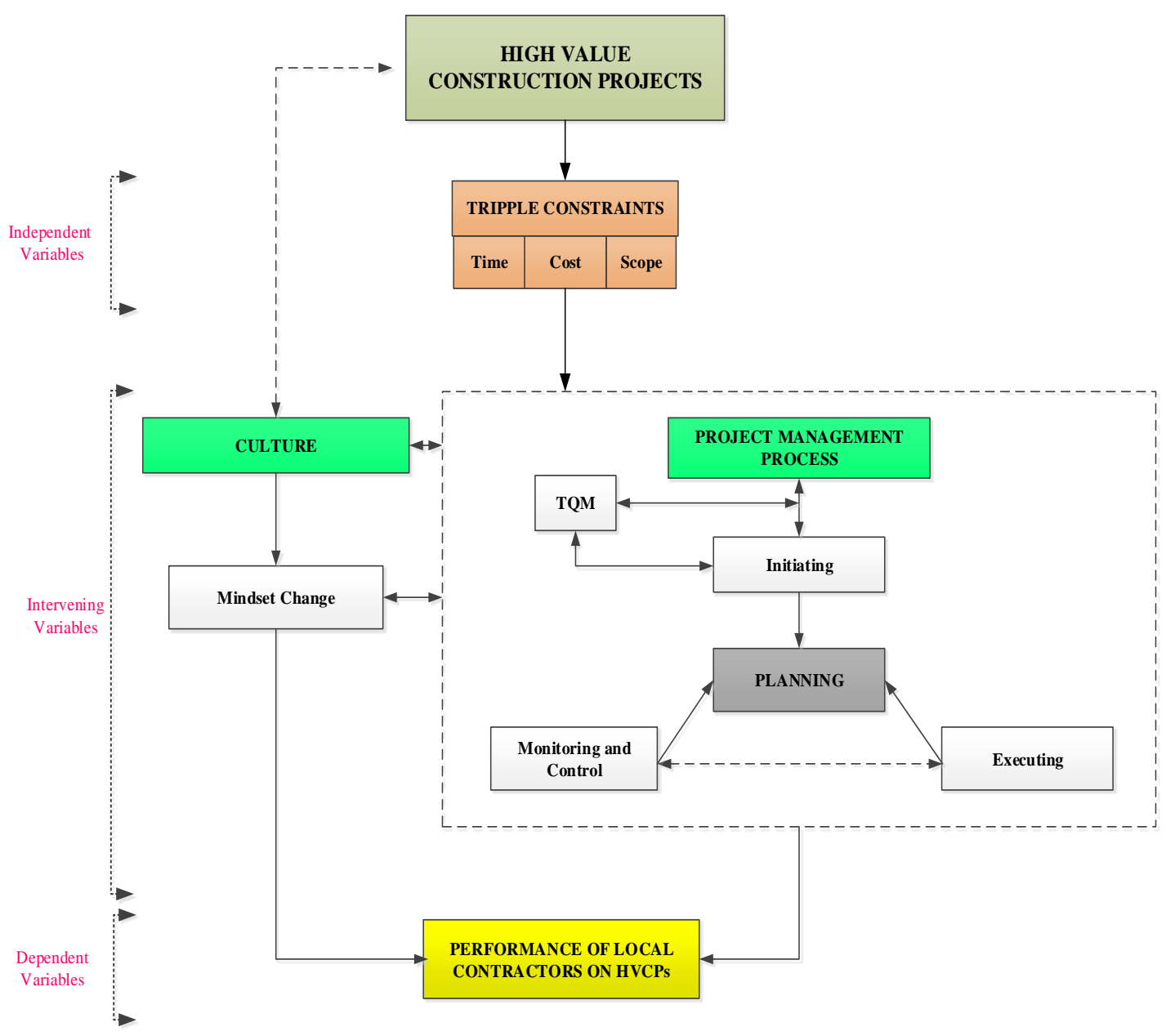

Figure 1. The conceptual framework, Source: Author, 2021

\subsection{RESEARCH METHODOLOGY}

During an academic investigation, the beliefs related to the nature of reality of the investigation influences the Research methodology, and ontology and epistemology are frequent themes of interest (UK dissertation writers, 2021). According to Saunders et al., (2019), Ontology is 'the nature of reality. Allison and Hobbs (2006) comment that ontological consideration is about "What is the nature of the knowable, or what the nature of reality is?" In this study, ontology and epistemology are presented because these create a holistic view of how knowledge is viewed and how individuals can see themselves about this knowledge, and the methodological strategies they use to discover it. On the other hand, Epistemology is a branch of philosophy 
concerned with studying the nature and limits of knowledge (Buckingham et al., 2011, Saunders et al., 2019). The selection of a philosophical stance would influence data collection and data analysis going forward. Therefore, the philosophy underpinning this study was pragmatism, defined as a deconstructive paradigm that advocates the use of mixed research methods (Feilzer 2010, Pp. 8) and "focuses instead on 'what works' as the truth regarding the study questions under investigation" (Teddlie and Tashakkori 2003b: Pp. 713). Therefore, this philosophy was relevant and valuable to this study. In this type of philosophy, reality exists, but it is ever-changing, based on people's actions. Thus, it attempts to find an enduring, external reality that is doomed to failure. The research design consisted of four phases were: comprehensive literature review, data collection, data analysis, development of the conceptual model to mitigate the factors that affect the performance of local contractors on high-value infrastructure projects, and arrived at the conclusions and recommendations. Therefore, this study adopted the survey strategy.

Nevertheless, the study population was 383 , including clients, consultants, and contractors who are the major players in the construction industry. Random and purposive sampling techniques were helpful in determing the sample size, and ultimately the Taro Yamane method for sample size calculation helped obtain a sample size. Consequently, the sample size for this study was 196. The collection of primary data was through the administration of structured questionnaires, which is typical for formal quantitative research, according to McDaniel and Gates (2012). The questionnaire was designed based on information originating from reviewed literature. It was designed in such a way that it had four (4) sections, i.e. section (A), (B), (C), (D) and (E). Section (A) comprised preliminary questions for the respondent, Section (B) addressed Cost performance on high-value construction projects, Section (C) focused on Time performance on high-value construction projects, while Section (D) looked at Quality performance on high-value construction projects and Section (E) addressed culture on construction projects. To distribute the questionnaires, it is not surprising that in some cases, phone and email were helpful to contact respondents. Besides, this approach has increasingly been used as a data collection medium because there are several significant benefits. The two most prominent benefits are cost-effectiveness and time efficiency (Taylor, 2002). Moreover, some researchers cite interviewing by telephone as an easy way to gather contextual information for quantitative studies because telephone interviews tend to take less time than face-to-face interviews (Sobo et al., 2003). Telephone interviews also have more minor personnel needs (Miller and Salkind, 2003). Thus, to enhance the questionnaire distribution, the researcher physically distributed a few questionnaires to the respondents and in a few cases utilised online platforms such as Google forms. The questionnaire was the best choice for data collection given the outbreak of the Covis-19. The researcher had no choice but adhere to the Covid-19 protocols such as social distance. However, there was care to ensure not mixing up the questionnaires and avoid repeating results. This approach was helpful in the 
process of collecting data from the target group. Furthermore, the study adopted mixed methods to triangulate the data and obtain information through different procedures to heighten the data's dependability and trustworthiness and interpretation. The collected data were analysed using descriptive and inferential statistics, computed using IBM Statistical Package (SPSS).

\subsection{RESEARCH RESULTS}

Out of the 196 questionnaires that were distributed, 123 responses were recived, giving a response rate of $62.76(63 \%)$. The following were the results:

\section{The challenges that influence performance on construction projects}

The questionnaire presented the respondents with a table that comprised some of the challenges that affected construction projects' performance. The priority scaling of the factors shown in the table was: $(1=$ Very low severity, 2 = Low severity, 3 = Medium severity, $4=$ High severity and $5=$ Very high severity). In addition,

\begin{tabular}{|c|c|c|c|c|c|c|c|}
\hline & & & 1 & 2 & 3 & 4 & 5 \\
\hline & & $\begin{array}{l}\text { Challenges } \\
\text { that influence } \\
\text { performance } \\
\text { on } \\
\text { construction } \\
\text { projects }\end{array}$ & $\begin{array}{l}\text { Poor site } \\
\text { management } \\
\text { practices }\end{array}$ & $\begin{array}{l}\text { Lack of } \\
\text { technical } \\
\text { expertise }\end{array}$ & $\begin{array}{l}\text { Poor } \\
\text { employee } \\
\text { development }\end{array}$ & $\begin{array}{l}\text { Organisational } \\
\text { culture }\end{array}$ & $\begin{array}{l}\text { Equipment } \\
\text { holding, }\end{array}$ \\
\hline $\mathrm{N}$ & Valid & & 123 & 123 & 123 & 123 & 123 \\
\hline & Missing & & 0 & 0 & 0 & 0 & 0 \\
\hline $\mathrm{M}$ & & & 3.83 & 3.80 & 3.62 & 3.89 & 3.89 \\
\hline & lian & & 4.00 & 4.00 & 4.00 & 4.00 & 4.00 \\
\hline $\mathrm{Su}$ & & & 471 & 467 & 445 & 478 & 478 \\
\hline
\end{tabular}

Table 1 The challenges that influence performance on construction projects, 1 to 5 . 
Table 2 The challenges that influence performance on construction projects, 5 to 10 .

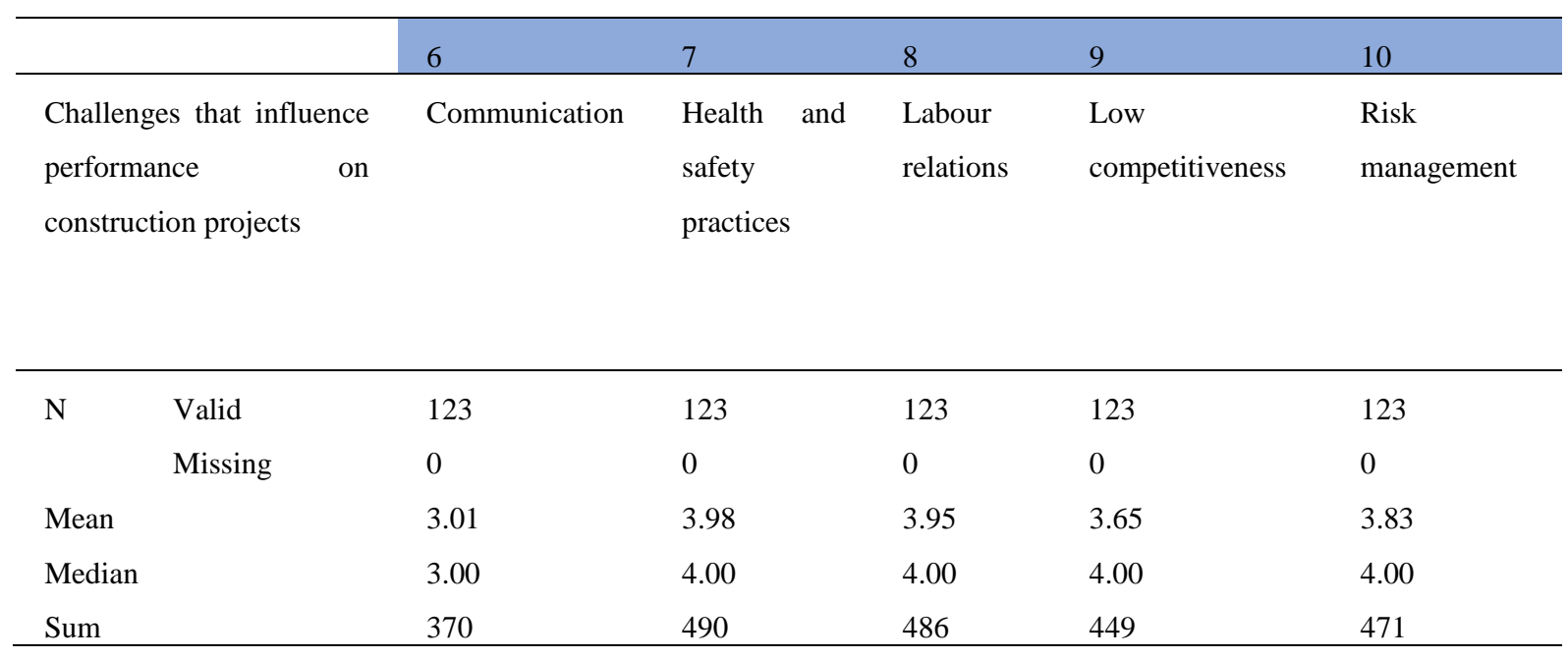

Table 3 The challenges that influence performance on construction projects, 11 to 15

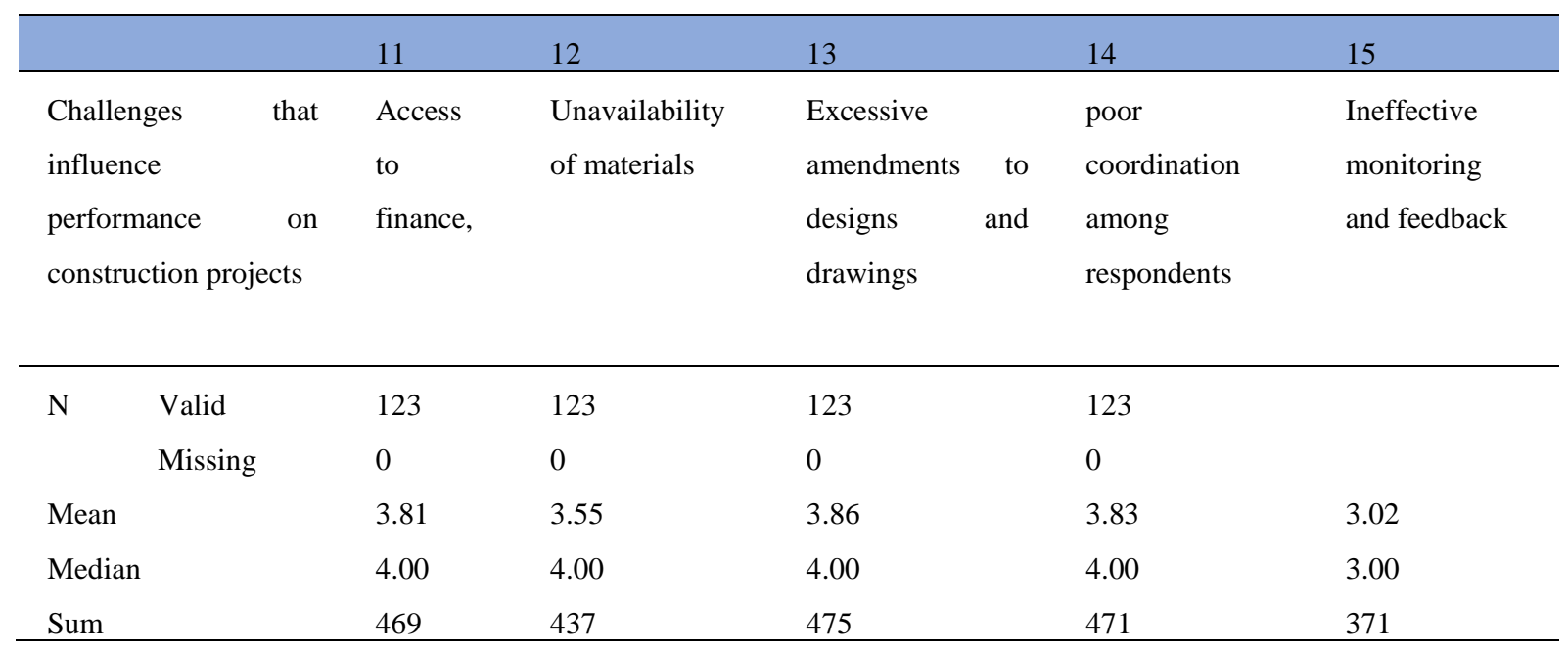


Table 4 The challenges that influence performance on construction projects, 16 to 22 .

\begin{tabular}{|c|c|c|c|c|c|c|c|c|}
\hline & 16 & 17 & 18 & 19 & 20 & 21 & 22 \\
\hline \multirow{3}{*}{\multicolumn{2}{|c|}{$\begin{array}{l}\text { Challenges } \\
\text { that influence } \\
\text { performance }\end{array}$}} & Lack of & Projects & Corruption & Vandalism & Constrained & Project & Poor \\
\hline & & leadership & failure & & & cash flow & uncertainty & supervision \\
\hline & & skills. & meet budget & & & & & \\
\hline \multicolumn{2}{|l|}{ on } & & and & & & & & \\
\hline \multicolumn{2}{|c|}{ construction } & & schedule & & & & & \\
\hline \multicolumn{2}{|c|}{ projects } & & expectations & & & & & \\
\hline \multirow[t]{2}{*}{$\mathrm{N}$} & Valid & 123 & 123 & 123 & 123 & 123 & 123 & 123 \\
\hline & Missing & 0 & 0 & 0 & 0 & 0 & 0 & 0 \\
\hline \multicolumn{2}{|c|}{ Mean } & 3.87 & 4.00 & 3.73 & 3.66 & 3.75 & 3.91 & 3.61 \\
\hline \multicolumn{2}{|c|}{ Median } & 4.00 & 4.00 & 4.00 & 4.00 & 4.00 & 4.00 & 4.00 \\
\hline \multicolumn{2}{|c|}{ Sum } & 476 & 492 & 459 & 450 & 461 & 481 & 444 \\
\hline
\end{tabular}

The above tables highlight the mean and median score for each of the challenges that influence the performance of contractors. However, the following charts highlight the exact responses for each of the factors, respectively.

Four different classifications of culture, namely, clan culture, adhocracy culture, market culture and hierarchy culture, were introduced to the respondents. The respondents were requested to define the work culture, which was best associated with their organisations. The following were the responses: Clan Culture $11.38 \%$, Adhocracy Culture 33.33\%, Market Culture, 14.63\%), Hierarchy Culture, $40.65 \%$ as shown in figure 2. 


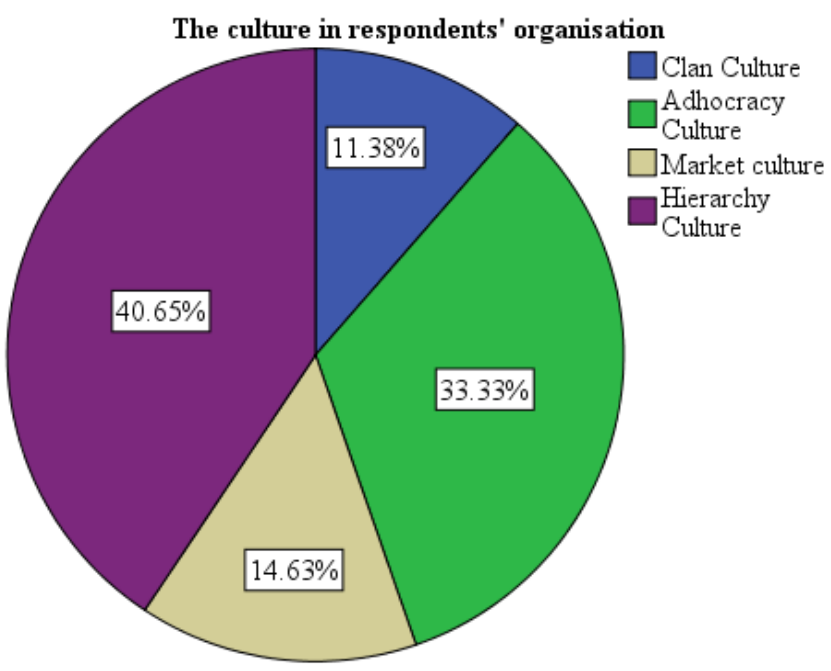

Figure 2 The culture in respondents organisation

\section{Culture has a bearing on the performance of organisations on construction projects}

The respondents were requested to state whether they thought culture affected construction projects' performance; the feedback was that $110(89.43 \%)$ indicated 'Yes' and $13(10.57 \%)$ selected 'No' as shown in the figure below.

Culture has a bearing on the performance on construction projects

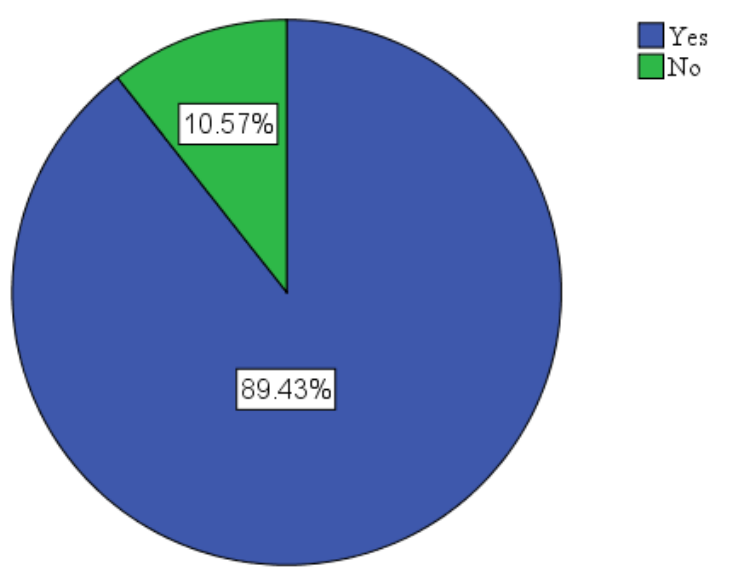

Figure 3 Culture has a bearing on the performance of contractors on construction projects 
How work culture affects the performance of local contractors on high-value construction projects

Respondents gave the following: Very low, 0\% (0), Low - 10.6\% (13), Average - 40.7\% (50), High - 39.8\%

(49), Very high $-8.9 \%$ (11) as illustrated in the figure below.

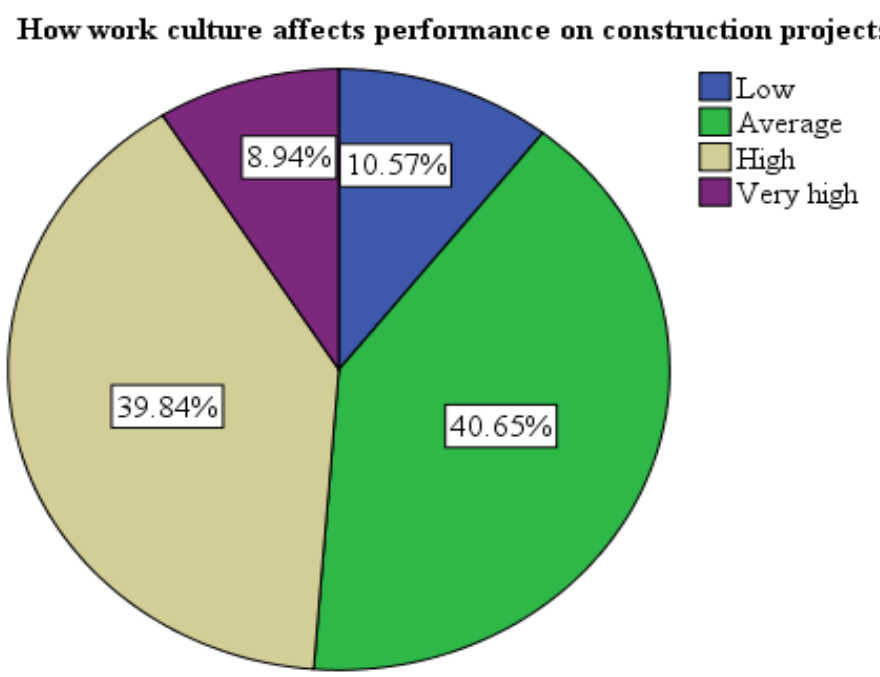

Figure 4 How work culture affects performance on construction projects

Respondents were requested to give additional comments on the preceding ranking question above, and the following was the feedback. Finally, 65 respondents of the 123 submitted their responses and were analysed using 'thematic analysis'. The following were the themes

Table 5 How culture affects the performance of local contractors on construction projects

\begin{tabular}{lllll}
\hline & Theme & Frequency $(\mathbf{f})$ & Percentile $(\mathbf{f} / \mathbf{n}) \mathbf{x}$ 100\% & $\begin{array}{l}\text { Other } \\
\text { Percentile }(\%)\end{array}$ \\
1 & Decision making & 50 & 77 & 23 \\
2 & Behaviour when advance payment is made & 65 & 100 & 0 \\
3 & Focus on work & 65 & 100 & 0 \\
4 & Confidence & 65 & 100 & 0 \\
5 & Innovation & 65 & 100 & 0 \\
6 & Transparency & 65 & 100 & 0 \\
7 & Financial management and consciousness to cost & 65 & 100 & 0 \\
\hline
\end{tabular}




\begin{tabular}{llccc}
\hline 8 & Adherence to time & 65 & 100 & 0 \\
9 & Definition of quality & 65 & 100 & 0 \\
10 & Action on risk management & 65 & 100 & 0 \\
11 & Staffing & 65 & 100 & 0 \\
12 & Work methods & 65 & 100 & 0 \\
13 & Response to project issues & 65 & 100 & 0 \\
14 & Mindset & 65 & 100 & 0 \\
15 & The general attitude towards work & 65 & 100 & \\
\hline
\end{tabular}

\section{Hypothesis testing:}

H0 $=$ Work culture affects the performance of local contractors on High-value construction projects

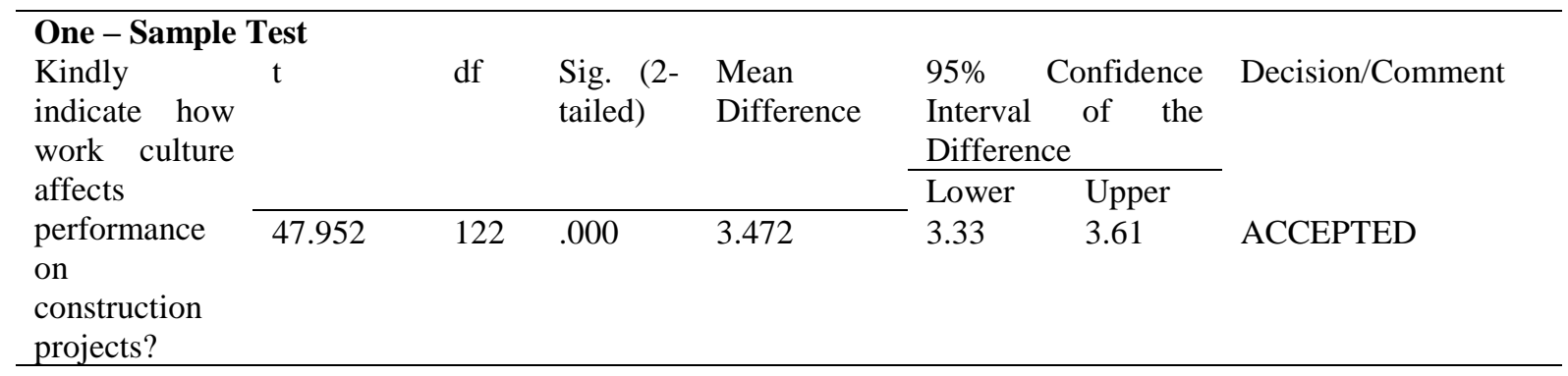

\section{The need for a mindset changes among some local contractors}

Respondents were requested to comment on the need for mindset change among some local contractors, and the results were as shown below:

$94.3 \%$ (116) responded with a 'Yes, while 5.7\% (7) gave this question a 'No'. 


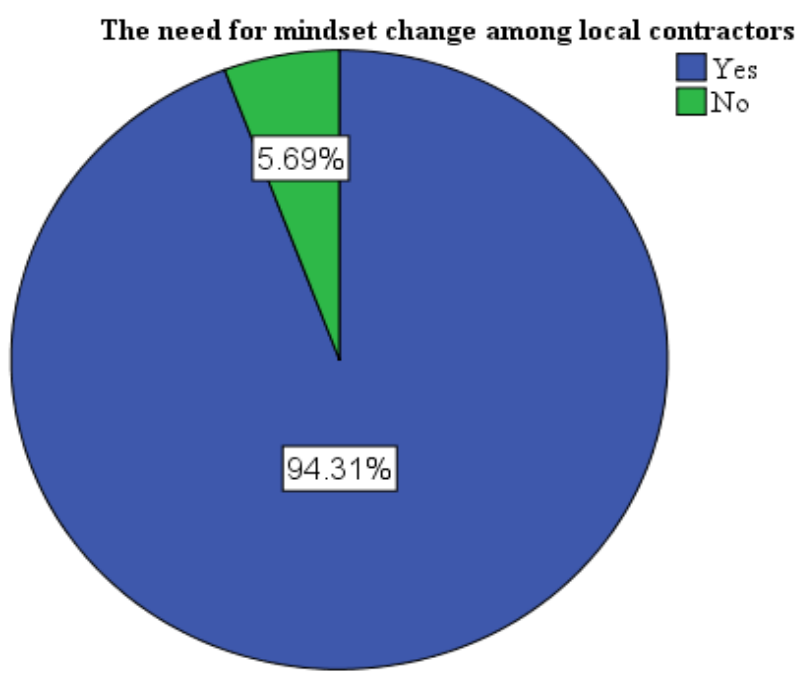

Figure 5. The need for mindset changes among some local contractors, Source: Author, 2021

\subsection{DISCUSSION OF RESULTS}

\section{Challenges that influence performance on construction projects}

Contractors encounter many challenges during project execution, and this is recognisable in the construction industry. The results gave an insight into some of the challenges which yielded a ranking of very high severity (5) and high severity (4), which included the following: Poor site management practices, lack of technical expertise, poor employee development, organisational culture, equipment holding, communication, health and safety practices, labour relations, low competitiveness, risk management, corruption, access to finance, excessive amendments to designs and drawings, ineffective monitoring and feedback, lack of leadership skills, and unavailability of materials, little or no utilisation of partnerships among local contractors to compete with foreign contractors and lack of enforcement of the subcontracting policy.

Interestingly, these results were consistent with current literature; for example, the PricewaterhouseCoopers (PWC) survey (2014) revealed that bribery and corruption are also deterrents to infrastructure investment in Africa as Chief Executive Officers (CEOs) in Africa and Latin America. The Middle East are more apprehensive about bribery and corruption than those in the rest of the world. Despite the development of new policies and regulations in many jurisdictions, corruption and security concerns continue to be significant challenges in some countries-Nigeria is an example of the countries that suffer from high levels of corruption. Similarly, with regards to the lack of skilled labour, the results agree with the assertions of the 
Infrastructure Consortium for Africa, 2015, Sichombo et al., (2009), Zambia Green Jobs Report (2015), and Construction Review online (2017, all of whom were of the view that the construction industry of Zambia suffers from the lack of skilled personnel. Therefore, this author suggests that more attention is needed to ensure that measures are put in place to address these challenges.

\section{Organisational culture and the work culture in the construction industry of Zambia}

The question prescribed four possible responses, namely: Hierarchy Culture, Market Culture, Adhocracy Culture and Clan Culture. The results showed that the dominant organisational culture in the construction industry of Zambia is the hierarchy culture which yielded $40.7 \%$ of respondents and was seconded by Adhocracy culture, $33.3 \%$. In the values matrix, the hierarchical culture is defined by stability and control and internal focus and integration. This type of culture values standardisation, control, and a well-defined structure for authority and decision making. Influential leaders in hierarchical cultures are those that can organise, coordinate, and monitor people and processes. Hierarchy culture also values efficiency, reliability, predictability and standardisation and the leaders are generally considered to be coordinators and organisers. This result is consistent with the findings of Maria Novana and Stephen Ogunlan (2003) who presented that the dominant culture of contracting companies in Thailand was hierarchical since they did not focus on innovation, growth, and resource acquisition. Such an organisation in the construction industry mainly stems from the clear lines of authority and respect for formal chains of command with centralised decision making where decision making is mainly the preserve of top and senior management. The nature of work is highly defined as it relates to the job descriptions and procedures. However, in contrast, Heyecan et al., (2010) revealed that the construction industry is dominated by clan and hierarchy cultures and that organisation culture differs in terms of the firm type, size and age. Although most respondents in this study selected hierarchy culture, with some local contractors this does not necessarily correspond with what is actually obtaining in their organisations. Moreover, during the literature review (Ankrah, opt. Cit), it was established that there is a common belief that the construction industry's culture is one of the factors that impact its performance; and that culture was one of the other significant factors that require attention in construction project management. Thus, local contractors must adopt a work culture that encourages hard work and better planning.

\section{Culture has a bearing on the performance of organisations on construction projects}

$110(89.43 \%)$ of the respondents indicated 'Yes'. Indeed, the result suggested that culture affects contractors' performance, and in many cases, it dictates the behaviour of working groups. This affirmation by the respondents suggests that the local contractors and their counterparts understand the right culture's need if 
performance is to be effective. Moreover, this result agrees with Fellows and Liu (2013) who argues that culture conditions behaviour, and then behaviour adjusts culture. This why it is important for construction organisations to give attention to their organisational culture. This author is of the opinion that this would ultimately determine their position with regards to values, norms and beliefs. It is the cultural background that would further determine how they can resist vices such as corruption and compromise of quality on a project.

\section{How culture affects the performance of local contractors on high-value construction projects}

The feedback from respondents was crucial to this study, and 70.7\% indicated high, and $8.9 \%$ indicated very high. This was a significant result as it entailed that culture plays a significant role in determining local contractor performance. This result appears to agree with the extant literature, notably Cameron and Quinn (1999), who stated that each quadrant of the CVF signifies company characteristics. The quadrants represent their basic assumptions, beliefs, and values, the stuff of culture. Thus, a good work culture would most certainly contribute to ensuring that projects are delivered on time, within cost and to the quality expectations set.

\section{The need for a mindset changes among some local contractors}

Based on the results, 94.31\% (116) of respondents said 'Yes. This is similar to the discussions in Chapter two (2), which noted a need to develop and massive structural and cultural shifts from traditional construction practices and systems to contemporary approaches (Kumaraswamy, 2006; Kumaraswamy et al., 2002; Ofori, 2000a). Since the construction industry is not an end in itself but a sector, it can be used to develop other sectors, and perhaps this could begin with a mindset change among local contractors. Mindset change requires understanding the entire construction cycle, projection of risks and understanding the project dynamics. In addition, the mindset must achieve high-quality products in the given time and at the cost first agreed with minimum impact to the environment.

Moreover, local contractors need to have confidence in themselves and commit to work they can manage to guarantee good performance and gain the trust of clients and other stakeholders. Thus, a shift in mindset is required to improve performance. Also, a mindset change from traditional approaches to dynamic and resultbased approaches is required among local contractors.

Additionally, contractors should enter the industry with a firm conviction that construction is a business and should be taken; directors need to acquire construction management skills to encourage understanding of works being ventured into and create a business environment to sustain the company. Additionally, they need to stop having a corrupt mind by ensuring that they refrain from paying bribes and stealing Engineers 
Curriculum Vitae.

Besides, the mindset change requires local contractors to move with technology innovation, to mention a few. They must carry out work with a mindset of making a product that will stand the taste of time. They should not do works only for monetary gain but rather do work that leaves a mark. There should be a program to inculcate the importance of hard work and its benefits; some Contractors focus on making money instead of delivering a good product at the end of the project. Furthermore, contractors need to eliminate excitement when implementing projects and understand the importance of project implementation. There is a need for businesses to save and plan for risk and not spend all the funds received. It is also inevitable for contractors to take care of staff on-site in order to curb stealing. Finally, they need to aspire to deliver projects on time, within budget and of good quality.

On the other hand, local contractors need to recognise that they can only stay in business and continue to profit if they do work to continue to derive profits from the projects they deliver. Whether public or private high-value projects, these will generate further projects only if they perform within the design and cost parameters. In the event of a failure, further business for local contractors will cease to exist. In addition to this, it was revealed that quality was not adequately considered as contractors tend to avoid quality checks.

Nevertheless, local Contractors need to develop a habit of putting the project first before profit. Opening dedicated Accounts for projects helps track project funds against the depositing of projects funds in the open and need to be considered by the local contractors. Besides, mindset change will entail contractors aiming to do work they will be proud of and not necessarily just getting a paycheque. Unfortunately, most local contractors execute purely on survival and not prestige to be realised from the project outcome hence resulting in an increase in substandard works.

Similarly, the respondents believed that it was difficult to state whether local contractors needed a mindset change as the respondents believed that local contractors had not been allowed to perform. Further, other respondents added that it is not the Contractors that need to change, but all stakeholders in the industry of which government is the most important.

\section{Hypothesis test}

Furthermore, because the mean difference (3.472) is within the lower (3.33) and upper (3.61) interval of the difference, the hypothesis that work culture affects the performance of local contractors on High-value construction projects was as accepted. 


\section{The influence of culture on the performance of contractors on high-value construction projects}

The first objective was to evaluate the influence of culture on the performance of contractors on high-value construction projects. This study established that hierarchical culture is dominant in construction organisations in the Zambian construction industry. Furthermore, the study established that culture influences the mindset of the local contractor as they venture into construction projects, the contractor's ability to apply project resources adequately, contractor flexibility to change, management of opportunities to work with foreign contractors who have more experience than them. Also, culture influences how contractors use the resources intended for construction projects - financial management. For instance, when other contractors invest in plant and equipment, some local contractors may be fond of spending the money on things not related to the project. Thus, this contributes to their inability, in most cases, to deliver projects within time, cost, and to the expected quality; culture influences how contractors address employee welfare, their leadership style and the openness of the contractor to invest in knowledge through training and continuous improvement.

Additionally, culture formulates the ethical conduct of local contractors and the study established that there is also a significant relationship between organisational culture and performance. This relationship could help a construction company cultivate an organisational culture that reduces time overruns, cost overruns, and quality shortfalls. It could also benefit international contractors relative to their expectations vis-à-vis time performance in projects undertaken in different countries.

\section{The significant challenges which local contractors encounter on high-value construction projects}

The second objective was to analyse the significant challenges which local contractors encounter on highvalue construction projects. The following were the challenges whose median was 4 (high severity): Poor site management practices, lack of technical expertise, Poor employee development, Organisational culture, Equipment holding, health and safety practices, Labour relations, Low competitiveness, Risk management, access to finance, unavailability of materials, Excessive amendments to designs and drawings, Poor coordination among respondents, lack of leadership skills, Projects failure to meet budget and schedule expectations, Corruption, Vandalism, Constrained cash flow, Project uncertainty and Poor supervision.

\subsection{CONCLUSION}

This study consulted with vast existing literature on contractor performance, which acknowledged the link between contractor performance and culture. Based on the survey results, the study concluded that organisational culture is a significant catalyst in the construction industry, and it influences the performance 
of contractors on high-value construction projects. Besides, most organisations in the construction industry of Zambia have a hierarchical culture that emphasised stability and efficiency instead of maintaining productivity and innovation. As a result, the organisations may find it difficult to survive in a fiercely competitive industry due to a mismatch between its cultural and environmental demands. Also, organisational culture influences how the contractor executes the project and manages the project's constraints, particularly aspects relating to time, cost, and quality of the project. Culture determines the contractors' response to project requirements, their mindset and work culture. Furthermore, it was established that understanding the culture of local contractors is necessary if they are to perform effectively and efficiently. Moreover, culture is a crucial enabler of the project's success in managing cost, time, quality, or project performance enhancement.

In addition, regarding the significant challenges local contractors encounter on high-value construction projects, the study concluded that persistent performance challenge begs whether the kind of project management that exists among local contractors is sufficient to meet the challenges of large projects. The significant challenges which local contractors encounter on high-value construction projects were: Poor site management practices, lack of technical expertise, poor employee development, organisational culture, equipment holding, health and safety practices, labour relations, low competitiveness, risk management, access to finance, unavailability of materials, excessive amendments to designs and drawings, poor coordination among respondents, lack of leadership skills, projects failing to meet budget and schedule expectations, corruption, vandalism, constrained cash flow, project uncertainty, and inadequate supervision.

\subsection{RECOMMENDATIONS}

Given the preceding, this study recommends that there is a need to improve the performance of local contractors in Zambia. Local contractors need to ensure that they undertake projects only after understanding the full extent of the scope and dedicate extra and relevant effort to the planning and monitoring projects to avoid or reduce time overruns, cost overruns and quality shortfalls. However, specific recommendations are below:

(a) Local contractors must work on balancing their organisational culture and their work culture. More efforts to improve work culture and local contractors ensure that they adopt a culture that can accommodate all four culture types. Considering that the culture on projects involves diverse teams, their success lies mainly in managing the diverse culture types and creating a combined culture that meets their needs. In this regard, local contractors should ensure a balanced organisational culture that allows them to be more reactive to their environments, especially to unforeseen changes, to improve their performance; 
(b) The construction industry should strive for a mindset change and good financial governance; there is a need, therefore, for contractors to invest in qualified personnel;

(c) Construction projects' challenges should be mitigated by attending to factors that influence cost overruns, time overruns, and quality shortfalls. Mitigation of challenges could be by ensuring that projects are adequately planned for, with confirmation, securing and rein fencing of funds for the project;

(d) There is a need for local contractors to engage qualified Project Managers with relevant experience in Project Management. In addition to this, there is a need for upgrading and enhancing the management capability, as it is vital for contractor growth and expansion in the construction industry;

(e) An appropriate performance appraisal system for contractors must be developed or enhanced, especially for public projects, to identify poorly performing contractors and make arrangements to build their capacity or suspended from participating in construction tenders;

(f) Capacity building and financial literacy programs for local contractors must be up-scaled to be conversant with construction projects' management practices and become accustomed to guaranteeing time, cost and quality;

(g) The Project Management team must ensure projects have insurance against performance liabilities such as cost overruns;

(h) More training opportunities for contractors and their project managers should be encouraged to serve as motivation, which will eventually boost their confidence, thereby eliminating the vices such as the practice of corruption and 'fronting' by local contractors who sell contracts to foreign contractors;

(i) Contractors should invest in the project team's motivation by involving them in activities throughout the project and planning frequent milestones. To that effect, the team would have a sense of ownership and responsibility for the project;

(j) Lastly, considering that drawings and specifications received from the consultants (Architects and Engineers) affect the construction quality and that the contractors' only source of the project design concept, size and scope are the drawings, there is a need for concise and uniform specifications. In addition, the designer (Architect/Engineer) must be familiar with the construction materials and techniques that the contractor will use to reduce unnecessary reworks and cost. 


\section{References}

Alqahtani F., Dr Ezekiel C, Prof. Sabah M, Dr David O., 2015, Factors Effecting Performance of Projects: A Conceptual Framework, International Journal of Scientific \& Engineering Research, Pp.670-674, Volume 6, Issue 4, April-2015 670 ISSN 22295518

Barney, J., 1991, Firm resources and sustained competitive advantage. Journal of Management. 17 (1), 99-120.

Burkiewicz, L, Knap-Stefaniuk, A., 2020, Modern Managers and Cultural Diversity in the Workplace. IN: Education Excellence and Innovation Management: A 2025 Vision to Sustain Economic Development during Global Challenges, The 35th IBIMA Conference on 1-2 April 2020 Seville, Spain. 7474-7483.

Butcher, D, Sheehan, M., 2010, Excellent contractor performance in the UK construction industry, Engineering, Construction and Architectural Management. 17. 35-45. 10.1108/09699981011011302.

Cameron, K.S, Elington, 1989, The Conceptual foundation of Organisational Culture in Higher Education: Handbook of theory and Research, Vol.4, Agathon Press, New York

Cameron, K.S., Quinn, R.E., 2011, Diagnosing and Changing Organizational Culture: Based on the Competing Values Framework, Jossey-Bass, San Francisco, CA.

Cameron, K S., Quinn, R E., 1999, Diagnosing and Changing Organizational Culture, New York: Addison-Wesley.

Cheung, S.O., Suen, H.C.H., Cheung, K.K.W., 2004, PPMS: a Web-based construction project performance monitoring system ', Automation in Construction, 13(3), 361- 376

Construction Review online, 2021, Top 5 challenges facing Africa's Construction Industry, https://constructionreviewonline.com/management/top-5-challenges-facing-africas-construction-industry/, accessed on $4^{\text {th }}$ March 2021

Edgar M., 2021, what is a problem? Available at: https://www.matthewedgar.net/problem/, Accessed 22.4.21

Edum-Fotwe, F. T., Thorpe, A, McCaffer, R., 2001, Information procurement practices of key actors in construction supply chains, European Journal of Purchasing \& Supply Management, 7(3), 155-164.

Faridi, A.S., El-Sayegh, S.M., 2006, "Significant factors causing delay in the UAE construction industry", Construction Management and Economics, Vol. 24 No. 11, pp. 1167-1176.

Feilzer, M Y., 2010, Doing mixed methods research pragmatically: Implications for the rediscovery of pragmatism as a research paradigm, Journal of Mixed Methods Research 4: 6-16

Fellows, R, Liu A., 2013, use and misuse of the concept of culture, Construction Management and Economics, 31. 10.1080/01446193.2013.794296.

Flyvbjerg, B., Skamris Holm, M. K., \& Buhl, S. L., 2003, how common and how large are cost overruns in transport infrastructure projects? Transport Reviews, 23(1), 71-88.

Gharakhani, D., Sinaki, M.T., Dobakhshari, M.A. and Rahmati, H., 2013, the Relationship of Customer Orientation, Customer Satisfaction, Customer Loyalty and Innovation in Small and Medium Enterprises ', Life Science Journal, 10(6s), 684-689.

Hanson, D., Mbachu, J., Nkando, R., 2003, Causes of client dissatisfaction in the South African Building industry and ways of improvement: the contractors'perspectives, in CIDB, South Africa 
Irefin, I. A., 2013, Effects of Project Management on the Performance of A Construction Firm in Nigeria, American International Journal of Contemporary Research, 3 (6), 54 - 58

Joseph, Owino \& Kibera, Francis. (2019), Organizational Culture and Performance: Evidence from Microfinance Institutions in Kenya, SAGE Open. 9. 215824401983593. 10.1177/2158244019835934.

Kemp, S., Dwyer, L., 2001, An examination of organisational culture - the Regent Hotel, Sydney, Int. J. Hosp. Manag 20 (1), 77-93

King M E, Manu R., 2019, Government project failure in developing countries: A review with particular reference to Nigeria, Global Journal of Social Sciences Vol 19, 2020: 35-47, DOI: https://dx.doi.org/10.4314/gjss.v19i1.4

KPMG, 2020, Budget highlights, Zambia, Road, Transport and Infrastructure, Pp. 12

McLoughlin C, Miura T., 2018, True Kaizen Management's Role in Improving Work Climate and Culture, Taylor \& Francis Group, LLC, International Standard Book Number-13: 978-1-138-74542-1 (Hardback)

Miller, D. C., Salkind, N. J., 2003, Handbook of research design and social measurement (6th Ed.), Thousand Oaks, CA: Sage

Musonda E., 2017, Local contractors need mindset change, Zambia Daily Mail, 13th January, 2017

National Council for Construction, Annual Report (2017), Pp.14-18

Patyal, V.S., Koilakuntla, M., 2018, "Impact of organisational culture on quality management practices: an empirical investigation", Benchmarking: An International Journal, Vol. 25 No. 5, pp. 1406-1428. https://doi.org/10.1108/BIJ-12-2016-0191

Pinto, S, Prescott, 2007, the elucidation of project success, International Journal of Project Management, 5(4), 757-775

PMBOK® Guide - Sixth Edition, 2017

PricewaterhouseCoopers - PWC, 2014, Trends, challenges and future outlook, Capital projects and infrastructure in East Africa, Southern Africa and West Africa, www.pwc.co.za/infrastructure November 2014

Project Management Institute (PMI), 2014, “A Guide to the Project Management Body of Knowledge” (PMBoK® guide) - fifth edition

Road Development Agency (RDA), 2015, 20 per cent mandatory sub-contracting guidelines

Saunders M, Lewis P, Thornhill A., 2019, Research Methods for Business Students, Eighth edition, ISBN: 978-1-292-20878-7, Pearson Education Limited, Pp.128-170

Sichombo, B., Muya, M \& Shakantu, W \& Kaliba, C., 2009, The Need for Technical Auditing in the Zambian Construction Industry, International Journal of Project Management. 27. 821-832. 10.1016/j.ijproman.2009.02.001.

Sinclair, M., Sinclair, C., 2009, Improving hotel efficiency through integration of service and project management cultures, Int. J. Hosp. Tour. 10 (4), 344-360

Sobo, E. J., Simmes, D. R., Landsverk, J. A., \& Kurtin, P. S., 2003, Rapid assessment with qualitative telephone interviews: Lessons from an evaluation of California's Healthy Families program \& Medi-Cal for Children, American Journal of Evaluation, 24(3), 399- 408 .

Taylor, A., 2002, I'll call you back on my mobile: A critique of the telephone interview with adolescent boys, Westminster Studies in Education, 25(1), 19-34.

Teddlie, C., Tashakkori, A., 2003b, the past and future of mixed methods research: From data triangulation to mixed model designs. In A. Tashakkori \& C. Teddlie (Eds.), Handbook of mixed methods in social \& behavioral research (pp. 671-713). Thousand 
Oaks, CA: Sage

Tharp, B. M., 2009, Four Organizational Culture Types, Retrieved 8th August, 2019, from Haworth online: http://www.haworth.com/enus/knowledge/workplace-library/Documents/Four-Organizational-Culture-\%20Types_6.pdf

The Globe, 2019, President Lungu concerned with shoddy construction works, article published on 6th December 2019, http://theglobeonline.news/uncategorized/president-lungu-concerned-with-shoddy-construction-works/ , accessed on $17^{\text {th }}$ February, 2020

United Nations Relief and Works Agency UNRWA, 2006, Projects Completion Reports, Gaza.

Zambia Construction Analysis Report, 2014, Good working conditions, Good business? An analysis of Zambia's building construction market system, November 2014, http://www.zambiagreenjobs.org/images/zambia/articoli/pdf/ZambiaConstrAnalysisReportNov2014.pdf, Pp. 4-6

Zambia Daily Mail, Audit of foreign contractors welcome, published on 24th May 2019, accessed on $27^{\text {th }}$ June 2019

Zambia Daily Mail, Contractors, need a mindset change, published on $13^{\text {th }}$ July 2017, http://www.daily-mail.co.zm/local-contractorsneed-mindset-change-2/, accessed on $27^{\text {th }}$ June 2019

Zambia Development Agency (ZDA) report of 2014 